\title{
Ductile Fe-Based Bulk Metallic Glass with Good Soft-Magnetic Properties
}

\author{
Tao Zhang*, Fengjuan Liu, Shujie Pang and Ran Li \\ Department of Materials Science and Engineering, Beijing University of Aeronautics and Astronautics, \\ Beijing 100083, P. R. China
}

We report a ductile Fe-Mo-P-C-B bulk metallic glass (BMG) with good soft-magnetic properties. The Fe-Mo-P-C-B BMG with high Poisson's ratio of 0.325 and low glass transition temperature of $708 \mathrm{~K}$ exhibits plastic strain up to $5.5 \%$ before final failure and high fracture strength of $3280 \mathrm{MPa}$ in compression. The Fe-based BMG possesses high saturation magnetization of $1.1 \mathrm{~T}$, low coercive force of $1.8 \mathrm{Am}^{-1}$ and high permeability of 55300. The Fe-Mo-P-C-B BMG with this combination of noticeable ductility, high strength and good soft-magnetic properties previously not observed simultaneously in Fe-based glassy alloys has promising potential in functional and structural applications. [doi:10.2320/matertrans.48.1157]

(Received January 19, 2007; Accepted March 12, 2007; Published April 25, 2007)

Keywords: Iron-based alloy, metallic glass, ductility, soft-magnetic property

\section{Introduction}

Among the numerous metallic glasses discovered in the last several decades, iron-based ones are commercially the most attractive because of their excellent magnetic properties, high strength, high corrosion resistance and relatively low cost. ${ }^{1-16)}$ Syntheses of iron-based metallic glasses with high glass-forming ability into a bulk form have further extended their potential applications as structural and functional materials. The first Fe-based bulk metallic glass (BMG) was reported in Fe-Al-Ga-P-C-B system in 1995, ${ }^{3)}$ subsequently a number of $\mathrm{Fe}$-based $\mathrm{BMGs}$ have been developed, such as Fe-Ga-P-C-B-Si and Fe-B-based BMGs with good soft-magnetic properties, ${ }^{4-8)}$ Fe-Cr-Mo-C-B BMGs with high corrosion resistance, ${ }^{9)}$ amorphous steel alloys with high GFA and high strength of 3000-4000 $\mathrm{MPa},{ }^{10-12)}$ and $\mathrm{Fe}-\mathrm{Co}-\mathrm{Nb}-\mathrm{Si}-\mathrm{B}$ BMGs with extremely high strength of over $4000 \mathrm{MPa} .{ }^{13)}$ A ternary boron-rich Fe-Nb-B BMG with strength near $4 \mathrm{GPa}$ was also recently reported. ${ }^{14)}$ Great efforts have been devoted to the search for ductile Febased BMGs for applications and fundamental studies. A few Fe-based BMGs with some ductility, such as Fe-Ga-P-C-B$\mathrm{Si}$, Fe-B-Si-Nb, Fe-Co-B-Si-Nb and Fe-Mo-C-B-Ln, have been reported. ${ }^{15-17)}$ In this work, $\mathrm{Fe}_{75} \mathrm{Mo}_{5} \mathrm{P}_{10} \mathrm{C}_{7.5} \mathrm{~B}_{2.5}$ bulk metallic glass with combined significant ductility, high strength and good soft-magnetic properties, which have not been found simultaneously in Fe-based glassy alloys reported up to date, was synthesized by copper mold casting. The $\mathrm{Fe}_{75} \mathrm{Mo}_{5} \mathrm{P}_{10} \mathrm{C}_{7.5} \mathrm{~B}_{2.5}$ BMG exhibited large plastic strain of $5.5 \%$ prior to final failure in compression, which could be attributed to the high Poisson's ratio of 0.325 and low glass transition temperature of $708 \mathrm{~K} .{ }^{17,18)}$ The Fe-based bulk metallic glass possesses high saturation magnetization of $1.1 \mathrm{~T}$, low coercive force of $1.8 \mathrm{Am}^{-1}$ and permeability up to 55300. This letter reports the formation, thermal stability, and mechanical and magnetic properties of the $\mathrm{Fe}_{75} \mathrm{Mo}_{5} \mathrm{P}_{10} \mathrm{C}_{7.5} \mathrm{~B}_{2.5}$ BMG.

*Corresponding author, E-mail: zhangtao@buaa.edu.cn (T. Zhang).

\section{Experiment Procedure}

$\mathrm{Fe}_{75} \mathrm{Mo}_{5} \mathrm{P}_{10} \mathrm{C}_{7.5} \mathrm{~B}_{2.5}$ alloy ingots were produced by induction melting mixtures of pure Fe (99.9 mass\%), Mo (99.9 mass\%), C (99.9 mass\%) and B (99.9 mass\%), and prealloyed Fe-P with known analyzed composition under a highpurity argon atmosphere. From the master alloy, ribbons were prepared by melt-spinning, and cylindrical rod and ringshaped samples were prepared by copper mold casting under an argon atmosphere. The structure of the specimens was examined by X-ray diffracometry (XRD) with $\mathrm{Cu}-\mathrm{K} \alpha$ radiation and transmission electron microscopy (TEM). Glass transition, crystallization and melting behaviors of the glassy samples were evaluated by differential scanning calorimetry (DSC) at a heating rate of $0.33 \mathrm{~K} / \mathrm{s}$. Compressive deformation tests were performed on a material test system (MTS) at a strain rate of $2.1 \times 10^{-4} \mathrm{~s}^{-1}$ at room temperature using glassy rods with a dimension of $1 \mathrm{~mm}$ in diameter and $2 \mathrm{~mm}$ in length. Samples subjected to compressive tests were observed by scanning electron microscopy (SEM). Ultrasound measurements were carried out to determine the elastic constants and the Poisson's ratio of the BMG. Saturation magnetization $\left(B_{\mathrm{s}}\right)$ was measured by a vibrating sample magnetometer (VSM) with a glassy rod of $1 \mathrm{~mm}$ in diameter. Coercive force $\left(H_{\mathrm{c}}\right)$ and DC permeability $\left(\mu_{\mathrm{DC}}\right)$ were evaluated by a DC B-H loop tracer using the glassy ringshaped samples. Structure and magnetic properties of the bulk glassy specimens annealed at a temperature of $\left(T_{\mathrm{g}}-50\right)$ $\mathrm{K}$ ( $T_{\mathrm{g}}$ is glass transition temperature) for 10 minutes were also examined.

\section{Results and Discussion}

Figure 1 shows outer shape, surface appearance and XRD patterns of the cast $\mathrm{Fe}_{75} \mathrm{Mo}_{5} \mathrm{P}_{10} \mathrm{C}_{7.5} \mathrm{~B}_{2.5}$ rods of $2 \mathrm{~mm}$ in diameter and rings with internal diameter of $10 \mathrm{~mm}$, external diameter of $13 \mathrm{~mm}$ and thickness of $1.2 \mathrm{~mm}$. The outer surfaces are smooth and no trace of precipitation of crystalline phase is seen. No appreciable diffraction peak corresponding to a crystalline phase is detected at the sensitivity of XRD. The wave vector defined as $K_{\mathrm{p}}=$ 

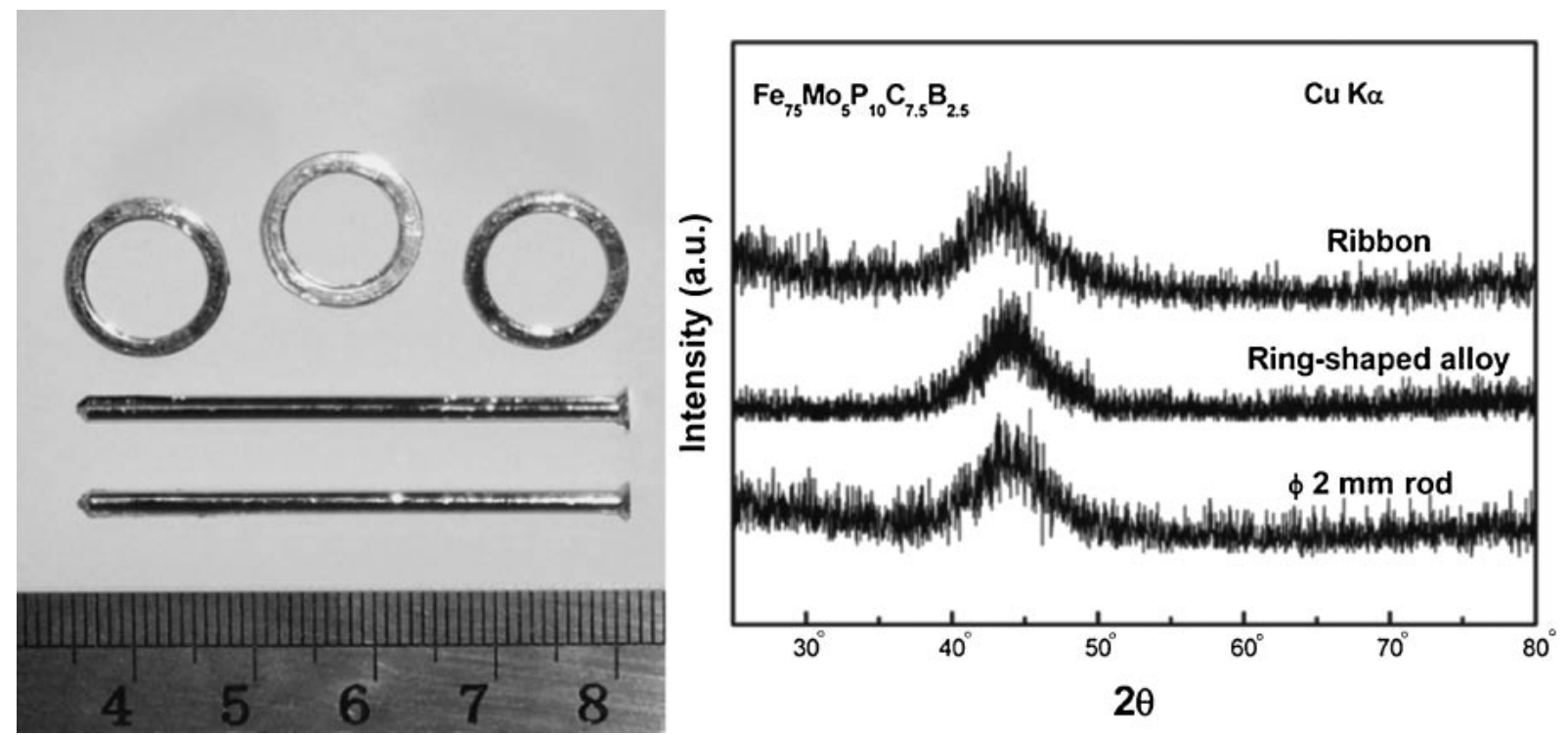

Fig. 1 Outer shape, surface appearance and X-ray diffraction patterns of cast $\mathrm{Fe}_{75} \mathrm{Mo}_{5} \mathrm{P}_{10} \mathrm{C}_{7.5} \mathrm{~B}_{2.5}$ alloy rods and ring-shaped samples.

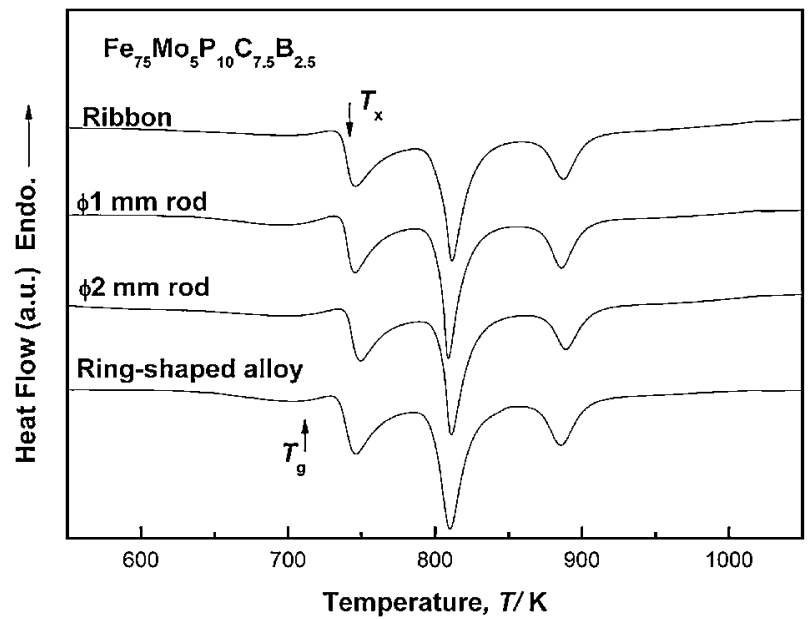

Fig. 2 DSC curves of $\mathrm{Fe}_{75} \mathrm{Mo}_{5} \mathrm{P}_{10} \mathrm{C}_{7.5} \mathrm{~B}_{2.5}$ alloy ribbon, ring-shaped sample and rods with diameters of $1 \mathrm{~mm}$ and $2 \mathrm{~mm}$.

$4 \pi \sin \theta / \lambda$ at the maximum of the main broad peak is measured as $56.58 \mathrm{~nm}^{-1}$ for the $\mathrm{Fe}_{75} \mathrm{Mo}_{5} \mathrm{P}_{10} \mathrm{C}_{7.5} \mathrm{~B}_{2.5}$ alloy. DSC curves of the $\mathrm{Fe}_{75} \mathrm{Mo}_{5} \mathrm{P}_{10} \mathrm{C}_{7.5} \mathrm{~B}_{2.5}$ specimens in bulk and ribbon forms are shown in Fig. 2, where $T_{\mathrm{x}}$ is onset temperature of crystallization. They show a distinct glass transition at $708 \mathrm{~K}$, followed by a supercooled liquid region of $32 \mathrm{~K}$ prior to crystallization at $740 \mathrm{~K}$. Moreover, no distinct difference in $T_{\mathrm{g}}, T_{\mathrm{x}}$ and total heat release of the main crystallization peaks $\Delta H_{\mathrm{x}}$ (about $110 \mathrm{Jg}^{-1}$ ) among the alloy rods of $2 \mathrm{~mm}$ and $1 \mathrm{~mm}$ in diameter, ring-shaped sample and the ribbon is detected, indicating the glassy single-phase nature of the bulk samples. Dark-field TEM image of the 2mm-diameter glassy rod was featureless and the selected area electron diffraction (SAED) pattern consisted only of a halo ring typical of amorphous phase. Based on the results of $\mathrm{XRD}$, DSC and TEM, it is concluded that the $\mathrm{Fe}_{75} \mathrm{Mo}_{5}-$ $\mathrm{P}_{10} \mathrm{C}_{7.5} \mathrm{~B}_{2.5}$ alloy rods with diameters up to $2 \mathrm{~mm}$ and the ring-shaped samples consist of a glassy-single phase. The melting point $\left(T_{\mathrm{m}}\right)$ and liquidus temperature $\left(T_{1}\right)$ of the alloy

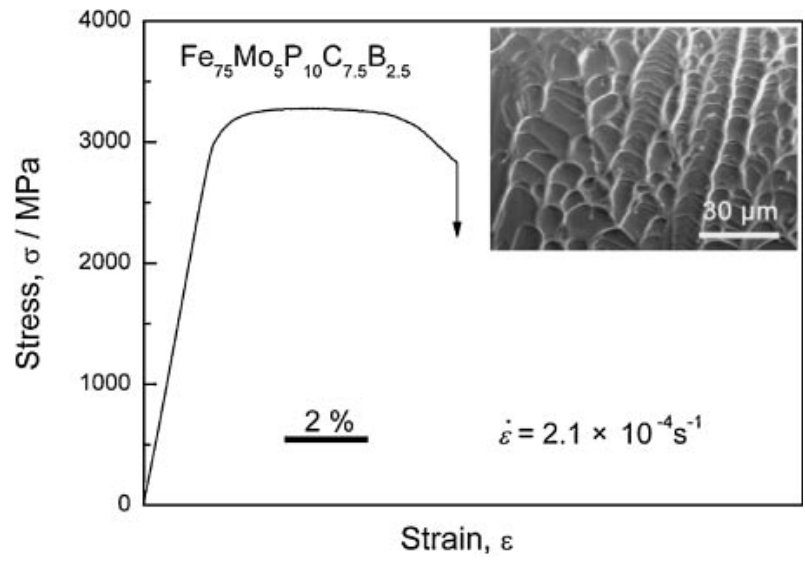

Fig. 3 Compressive stress-strain curve of bulk glassy $\mathrm{Fe}_{75} \mathrm{Mo}_{5} \mathrm{P}_{10} \mathrm{C}_{7.5} \mathrm{~B}_{2.5}$ rod with a diameter of $1 \mathrm{~mm}$ and SEM image of the fracture surface appearance.

were measured to be $1209 \mathrm{~K}$ and $1258 \mathrm{~K}$, respectively. It is notable that $T_{\mathrm{g}}, T_{\mathrm{m}}$ and $T_{1}$ of the present $\mathrm{Fe}_{75} \mathrm{Mo}_{5} \mathrm{P}_{10} \mathrm{C}_{7.5} \mathrm{~B}_{2.5}$ glassy alloy are the lowest among the Fe-based bulk glassy alloys reported up to date, and this is advantageous in practical application.

Figure 3 shows stress-strain curve of glassy $\mathrm{Fe}_{75} \mathrm{Mo}_{5}-$ $\mathrm{P}_{10} \mathrm{C}_{7.5} \mathrm{~B}_{2.5}$ rod with a diameter of $1 \mathrm{~mm}$ under compressive loading. Initially, the curve behaves like a typical Fe-based BMG, exhibiting an elastic strain of about $2 \%$ at yield strength of $3080 \mathrm{MPa}$. However, it is notable that after yielding and even after reaching the maximum strength of $3280 \mathrm{MPa}$, the material did not catastrophically fracture but deform in a plastic manner. The plastic strain prior to final failure is as large as about $5.5 \%$. Such significant plasticity has not been observed previously for Fe-based BMGs. The inset in Fig. 3 shows the fracture surface appearance and well-developed vein pattern can be seen, which is typical of fracture surface for ductile BMGs. Many liquid-like droplets are also observed on the fracture surface, implying local softening and melting during compression. Figure 4 shows 

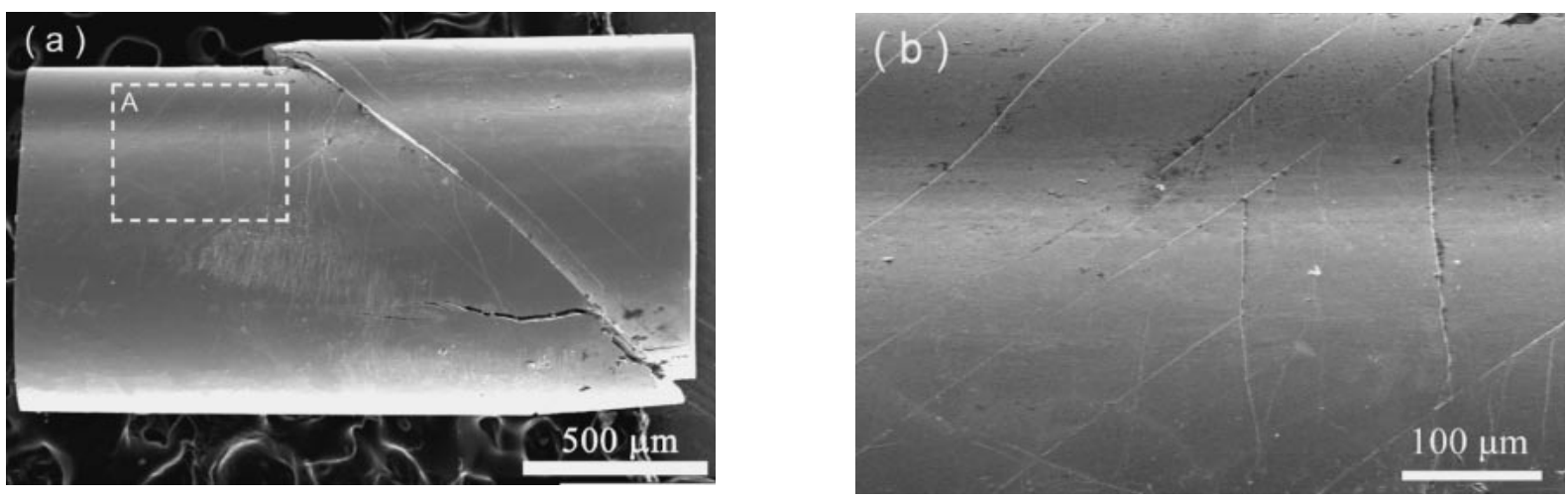

Fig. 4 SEM images of surface appearance of bulk glassy $\mathrm{Fe}_{75} \mathrm{Mo}_{5} \mathrm{P}_{10} \mathrm{C}_{7.5} \mathrm{~B}_{2.5}$ alloy loaded to plastic strain of $4.5 \%$. (b) is the enlarged image of area $\mathrm{A}$ in (a).

SEM images of the surface of a glassy $\mathrm{Fe}_{75} \mathrm{Mo}_{5} \mathrm{P}_{10} \mathrm{C}_{7.5} \mathrm{~B}_{2.5}$ rod sample loaded to $4.5 \%$ strain in compression. A number of shear bands can be observed on the deformed sample surface. The primary shear bands are declined by about $45^{\circ}$ to the direction of the applied load, and the secondary shear bands formed at an angle of about $45^{\circ}$ with respect to the primary shear bands. The sample also shows shear slide along a main shear plane orient at about $45^{\circ}$ to the stress axis, which may lead to the stress decrease beyond $\sim 4 \%$ plastic strain on the stress-strain curve. It is suggested that the formation of high density of shear bands and the shear slide along a primary shear plane during compression contribute to the significant plasticity of the present Fe-based glassy alloy.

In conventional crystalline metals, high Poisson's ratio (v) is a phenomenological indicator of inherent ductility. This parameter was found to be also suitable for ductile metallic glasses. ${ }^{17-19)}$ It was reported that Poisson's ratio of some ductile metallic glasses was larger than $0.31-0.32 .{ }^{18)}$ For FeMo-C-B-Ln BMG systems, an onset of plasticity at Poisson's ratio approaching 0.32 from below was revealed. ${ }^{17)}$ In this work, the Poisson's ratio of the $\mathrm{Fe}_{75} \mathrm{Mo}_{5} \mathrm{P}_{10} \mathrm{C}_{7.5} \mathrm{~B}_{2.5} \mathrm{BMG}$ was determined to be 0.325 , which is higher than the critical value 0.32 and the corresponding plastic strain is as large as $5.5 \%$ (shown in Fig. 3). This result further supports that higher Poisson's ratio corresponds to better ductility for $\mathrm{Fe}$ based BMGs as in conventional crystalline metals. On the other hand, it has been suggested ${ }^{19,20)}$ that BMGs with low $T_{\mathrm{g}}$ values are more likely to exhibit ductility. Compared with other iron-based BMGs, ${ }^{1-5,8-16)}$ the ductile $\mathrm{Fe}_{75} \mathrm{Mo}_{5}$ $\mathrm{P}_{10} \mathrm{C}_{7.5} \mathrm{~B}_{2.5}$ glassy alloy exhibited lower $T_{\mathrm{g}}$ of $708 \mathrm{~K}$, conformity with the correlation between ductility and $T_{\mathrm{g}}$ to other ductile BMGs. ${ }^{19,20)}$

Figure 5 exhibits the hysteresis $B-H$ curves of the $\mathrm{Fe}_{75} \mathrm{Mo}_{5} \mathrm{P}_{10} \mathrm{C}_{7.5} \mathrm{~B}_{2.5} \mathrm{BMG}$, and the inset is hysteresis branches of the ring shaped samples near zero field showing the coercive force. It is indicated that the $\mathrm{Fe}_{75} \mathrm{Mo}_{5} \mathrm{P}_{10} \mathrm{C}_{7.5} \mathrm{~B}_{2.5}$ BMG possesses good soft-magnetic properties. The as-cast Fe-based BMG shows high saturation magnetization $\left(B_{\mathrm{s}}\right)$ of $1.1 \mathrm{~T}$, low coercive force $\left(H_{\mathrm{c}}\right)$ of $6.8 \mathrm{Am}^{-1}$ and high DC permeability $(\mu)$ of 47000 . After annealing at $\left(\mathrm{T}_{\mathrm{g}}-50\right) \mathrm{K}$ (i.e. $658 \mathrm{~K}$ ) for 10 minutes, the Fe-based $\mathrm{BMG}$ maintained glassy structure, which was revealed by XRD, DSC and TEM examinations, and the soft-magnetic properties were further

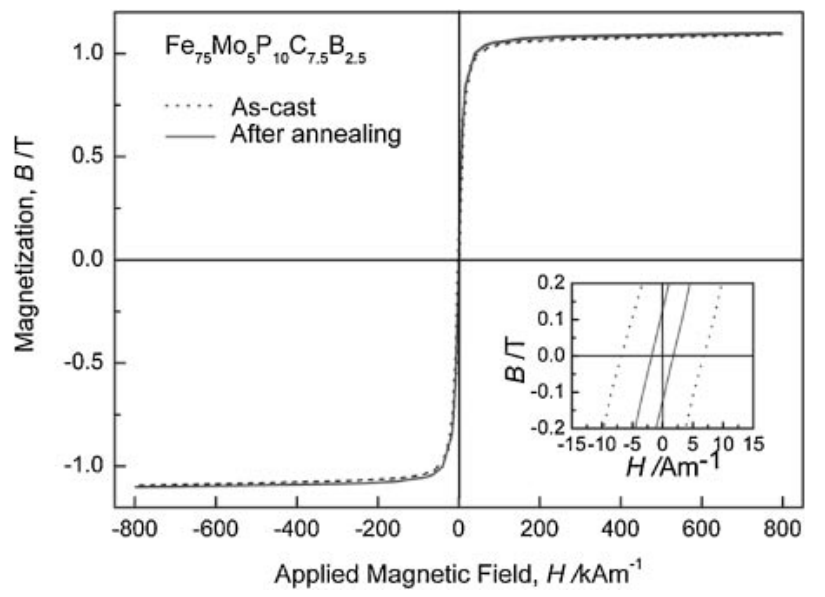

Fig. 5 Hysteresis $B-H$ curves of $\mathrm{Fe}_{75} \mathrm{Mo}_{5} \mathrm{P}_{10} \mathrm{C}_{7.5} \mathrm{~B}_{2.5} \mathrm{BMG}$ with inset of hysteresis branches of the ring-shaped samples near zero field.

improved, i.e. $H_{\mathrm{c}}$ decreases to $1.8 \mathrm{Am}^{-1}$ and $\mu_{\mathrm{DC}}$ increases to 55300 while $B_{\mathrm{s}}$ keeps at $1.1 \mathrm{~T}$.

\section{Conclusions}

In summary, ductile $\mathrm{Fe}_{75} \mathrm{Mo}_{5} \mathrm{P}_{10} \mathrm{C}_{7.5} \mathrm{~B}_{2.5} \mathrm{BMG}$ with high strength and good soft-magnetic properties has been successfully synthesized by copper mold casting. The $\mathrm{Fe}_{75} \mathrm{Mo}_{5}-$ $\mathrm{P}_{10} \mathrm{C}_{7.5} \mathrm{~B}_{2.5} \mathrm{BMG}$ exhibited a plastic strain to final failure up to $5.5 \%$ and high strength of $3280 \mathrm{MPa}$ in compression. Multiple shear bands and distinct shear slide were observed on the deformed specimens. The significant plasticity could be attributed to the high Poisson's ratio of 0.325 and low glass transition temperature of $708 \mathrm{~K}$. After annealing, the Fe-based BMG shows high saturation magnetization of $1.1 \mathrm{~T}$, low coercive force of $1.8 \mathrm{Am}^{-1}$ and high permeability of 55300. The Fe-based glassy alloy with combined ductility, high strength and good soft-magnetic properties is promising for applications as a functional and structural material.

\section{Acknowledgements}

The authors would like to thank Professor A. R. Yavari at Institut National Polytechnique de Grenoble, France for useful discussions. Financial support from National Nature 
Science Foundation of China (50471001 and 50631010) and Program for Changjiang Scholars and Innovative Research Team in University (IRT0512) are gratefully acknowledged.

\section{REFERENCES}

1) A. Inoue: Bulk Amorphous Alloys: Practical Characteristics and Applications (Trans Tech Publications Ltd., Switzerland, 1999), pp. 180

2) W. L. Johnson: JOM 54 (2002) 40.

3) A. Inoue, Y. Shinohara and J. S. Gook: Mater. Trans., JIM 36 (1995) 1427-1433.

4) B. L. Shen and A. Inoue: Mater. Trans. 43 (2002) 1235-1239.

5) C. Y. Lin, H. Y. Tien and T. S. Chin: Appl. Phys. Lett. 86 (2005) 162501.

6) H. Chiriac, N. Lupu and M. Tibu: IEEE Trans. Magn. 39 (2003) 3040 3042 .

7) A. Inoue and K. Hashimoto: Amorphous and Nanocrystalline Materials: Preparation, Properties, and Applications (Springer-Verlag, Berlin, 2001) pp. 34-38.

8) B. L. Shen, M. Akiba and A. Inoue: J. Appl. Phys. 100 (2006) 043523.
9) S. J. Pang, T. Zhang, K. Asami and A. Inoue: Acta Mater. 50 (2002) 489-497.

10) Z. P. Lu, C. T. Liu, J. R. Thompson and W. D. Porter: Phys. Rev. Lett. 92 (2004) 245503.

11) V. Ponnambalam, S. J. Poon and G. J. Shiflet: J. Mater. Res. 19 (2004) 1320-1324.

12) J. Shen, Q. chen, J. F. Sun, H. B. Fan and G. Wang: Appl. Phys. Lett. 86 (2005) 151907.

13) B. L. Shen and A. Inoue: Appl. Phys. Lett. 85 (2004) 4911.

14) M. Stoica, K. Hajlaoui, A. LeMoulec and A. R. Yavari: Phil. Mag. Lett. 86 (2006) 267-275.

15) K. Amiya, A. Urata, N. Nishiyama and A. Inoue: Mater. Trans. 45 (2004) 1214-1218.

16) A. Inoue, B. L. Shen, A. R. Yavari and A. L. Greer: J. Mater. Res. 18 (2004) 1487-1492.

17) X. J. Gu, A. G. McDermott, S. J. Poon and G. J. Shiflet: Appl. Phys. Lett. 88 (2006) 211905.

18) J. J. Lewandowski, W. H. Wang and A. L. Greer: Phil. Mag. Lett. 85 (2005) 77-87.

19) J. Schroers and W. L. Johnson: Phys. Rev. Lett. 93 (2004) 255506.

20) B. Zhang, D. Q. Zhao, M. X. Pan, W. H. Wang and A. L. Greer: Phys. Rev. Lett. 94 (2005) 205502. 